\title{
An audit on transfers from peripheral hospitals to a paediatric unit, Teaching Hospital, Kandy
}

\author{
M I Rifaya ${ }^{1}$, S K Rajapaksa ${ }^{2}$, G L D C Prematilaka ${ }^{3}$, U G D S Manawasinghe3, N S Balasooriya ${ }^{3}$ \\ Sri Lanka Journal of Child Health, 2011; 40(4): 169-171
}

\begin{abstract}
Introduction: Many patients are transferred to Teaching hospital, Kandy (THK) from peripheral hospitals for investigation and specialized management.
\end{abstract}

Objectives: To study the pattern of transfers from peripheral hospitals to a paediatric unit in THK and the outcome of management of these transfers.

Method: A prospective observational study based on questionnaires was carried out from May to July 2007on children transferred from peripheral hospitals to a paediatric unit in THK. Questionnaires were completed by one of the investigators on admission and on discharge.

Results: The study population comprised 146 transferred children, $84 \%$ from district and rural hospitals and $16 \%$ from base and general hospitals. Forty five percent were admitted outside working hours and $75 \%$ were preschoolers. Eighty six percent of transfers were for further management. Fifty nine percent were transferred on the first day of admission. Thirty one percent had respiratory tract infections, $14 \%$ febrile convulsions and $10 \%$ gastroenteritis. Seventy percent needed basic medical treatment on admission. Only 3\% needed intensive care. Fifteen percent had basic investigation results on admission. Sixty five percent were discharged during first two days. Forty eight percent had respiratory tract infections as the final diagnosis. Forty one percent of the transfer forms were well completed with necessary information. In 19\% the designation of the transferring officer was not mentioned.

\footnotetext{
${ }^{1}$ Senior Registrar in Paediatrics, ${ }^{2}$ Consultant Paediatrician, ${ }^{3}$ Intern Medical Officer, Teaching Hospital, Kandy
}

(Received on 3 December 2010: Accepted on 25 February 2011)
Conclusions: Most transfers were from rural and district hospitals and the main reason for transfer was investigation and further management of respiratory tract infection. Transferring officers need to pay more attention to essential information when filling the forms.

(Key words: transfer, teaching hospital, transfer form)

\section{Introduction}

Teaching hospital, Kandy (THK) provides specialized health care services to the adjoining provinces. A considerable number of patients are transferred to this hospital for investigation and specialized management. This hospital has two paediatric medical units, a neonatology unit and a paediatric surgical unit. Each paediatric medical unit has on an average 30 admissions per day.

\section{Objectives}

To study the pattern of transfers from peripheral hospitals to a paediatric unit, THK and to assess the outcome of management of these transfers

\section{Method}

A questionnaire-based prospective observational audit was carried out from May to July 2007 on children transferred from peripheral hospitals to a paediatric unit, THK. Information was gathered on demographic data, reason for transfer, investigation results available at the time of transfer, documentation of necessary information on the transfer form and the outcome of those transfers. Questionnaires were completed by one of the investigators on admission and on discharge.

\section{Results}

Of 980 admissions to the paediatric unit during the study period $146(15 \%)$ were transfers from 
peripheral hospitals. The types of peripheral hospitals from which transfers occurred are shown in table 1.

Table 1

Type of peripheral hospital

\begin{tabular}{|c|c|}
\hline Peripheral hospital & No. of patients (\%) \\
\hline General & $12(08)$ \\
\hline Base & $12(08)$ \\
\hline District & $96(66)$ \\
\hline Rural & $26(18)$ \\
\hline
\end{tabular}

Seven percent were first admitted to the emergency treatment unit (ETU). Forty five percent were admitted outside working hours (between 4pm-8am). The age groups of the transferred patients are shown in table 2.

Table 2

Age Groups of the transfers

\begin{tabular}{|c|c|}
\hline Age group & No. of patients (\%) \\
\hline$<1$ year & $48(33)$ \\
\hline $1-5$ years & $61(42)$ \\
\hline$>5$ years & $37(25)$ \\
\hline
\end{tabular}

The reasons for the transfer are shown in table 3 .

Table 3

Reasons for transfer

\begin{tabular}{|l|c|}
\hline Reason for transfer & No. of patients (\%) \\
\hline $\begin{array}{l}\text { Investigation \& further } \\
\text { management }\end{array}$ & $125(86)$ \\
\hline Intensive care & $06(04)$ \\
\hline Due to long weekend & $06(04)$ \\
\hline Unknown & $09(06)$ \\
\hline
\end{tabular}

Fifty nine percent were transferred on the first day of admission, $31 \%$ on $2^{\text {nd }}$ and $3^{\text {rd }}$ days and $10 \%$ after the $3^{\text {rd }}$ day of admission. The diagnoses at the time of transfer are shown in table 4.

Table 4

Tentative diagnosis at the time of transfer

\begin{tabular}{|l|c|}
\hline \multicolumn{1}{|c|}{ Diagnosis } & No. of patients (\%) \\
\hline Respiratory tract infections & $45(31)$ \\
\hline Febrile convulsions & $20(14)$ \\
\hline Acute gastroenteritis & $15(10)$ \\
\hline Poisoning & $10(07)$ \\
\hline Urinary tract infections & $04(03)$ \\
\hline Afebrile convulsions & $03(02)$ \\
\hline Typhoid & $02(01)$ \\
\hline Other & $14(09)$ \\
\hline None & $33(23)$ \\
\hline
\end{tabular}

Out of 45 who had respiratory tract infection as the tentative diagnosis, 13 (29\%) had asthma, 5 (11\%) had bronchiolitis, 12 (27\%) had pneumonia, 8 (18\%) had upper respiratory tract infections (URTI) and 7 $(16 \%)$ had lower respiratory tract infections (LRTI).

The final diagnoses at the time of discharge are shown in table 5 .

Table 5

Final diagnosis at the time of discharge

\begin{tabular}{|l|c|}
\hline Final diagnosis & No. of patients \\
\hline Febrile fit & 20 \\
\hline Asthma & 15 \\
\hline Pneumonia & 15 \\
\hline URTI & 15 \\
\hline LRTI & 15 \\
\hline Acute gastroenteritis & 15 \\
\hline Bronchiolitis & 10 \\
\hline Poisoning & 10 \\
\hline Viral fever & 06 \\
\hline Urine infection & 04 \\
\hline Afebrile convulsion & 03 \\
\hline Typhoid & 02 \\
\hline Others & 16 \\
\hline
\end{tabular}

Seventy percent needed basic medical treatment on admission. Twenty one percent needed intravenous (IV) antibiotics, 4\% IV fluid boluses, 15\% IV fluid maintenance, 51\% nebulization and 9\% oxygen. Fifteen percent had basic investigation results on admission $(50 \%$ had blood test, $27 \%$ had urine test and $23 \%$ had $\mathrm{x}$ - ray). Only $3 \%$ needed intensive (ICU) care. Significant changes in diagnosis and management were made only in $39(27 \%)$ cases. Forty eight percent had respiratory tact infection as the final diagnosis.

Sixty five percent were discharged during the first two days after admission and $15 \%$ on the $3^{\text {rd }}$ day after admission. Twenty percent stayed for more than 3 days for investigation and further management. There were no deaths.

Analysis of the transfer forms showed the following: $28 \%$ were well completed with necessary information, $52 \%$ had inadequate information and $20 \%$ were not completed at all. The designation of the transferring officer was not mentioned in $19 \%$ of the transfer forms. 


\section{Discussion}

There are very few studies in Sri Lanka on transfers from peripheral hospitals to teaching hospitals ${ }^{1,2}$. Our audit showed that the majority of the transfers were from rural and district hospitals for the management of respiratory tract infections. The main reason for such transfers was non-availability of basic investigation and management facilities which is probably the reason for the majority of transfers occurring on the first day of admission. By providing basic treatment facilities such as nebulization, oxygen and IV antibiotics we can improve the quality of care in these hospitals. We also stress on the necessity of completing the transfer form with all relevant clinical information as this influences the patient care in the receiving hospital.

\section{Conclusions}

- Majority of transfers were from rural and district hospitals and the main reason for transfer was investigation and further management of respiratory tract infection.

- Most cases were transferred on the $1^{\text {st }}$ day of admission as many local hospitals lack basic investigation and management facilities.

- The transferring officers need to pay special attention to essential information when filling the transfer forms.

\section{References}

1. Sudewa LL, Nelundeniya NPUBP, Perera B J C, Weerasinghe I. A survey of transfer forms at the Lady Ridgeway Hospital for Children. Sri Lanka Journal of Child Health, 2003; 32: 44-7.

2. SellahewaKH, Lamabadusuriya SP, Edirisinghe EASK. Transfers to a general medical ward at National Hospital of Sri Lanka: A descriptive study. Galle Medical Journal, September 2009; 14 (1): 